\title{
Optimal management of benign paroxysmal positional vertigo patients: An unmet need
}

\author{
Sheikh Hilal Ahmad, Ahmad S Bashir, Sajad Tak, Henna Naqash \\ Department of Neurology ,Super Speciality Hospital , GMC Srinagar, J\&K.
}

\section{A B S T R A C T}

Background: Benign paroxysmal positional vertigo (BPPV) is considered to be the most common type of vertigo. There is strong evidence supporting the role of Dix Hallpike maneuver in diagnosing BPPV, and canalith repositioning maneuver CRM in managing it; but these maneuvers are underutilized.

Material and Methods: A prospective study was conducted in the Department of Neurology in a tertiary care center referral hospital in Kashmir, north India. All the patients of vertigo diagnosed as BPPV were included in study. Detailed history was taken and examination was done and patients were followed to see the response of treatment. Their referrals notes, previous records were studied for the diagnosis, treatment and investigations done for managing their complaints.

Results: Out of total of 101 patients diagnosed as BPPV, 77 were females and 24 were males with M:F ratio as 1:3.2. The frequency of various subtypes of BPPV were: posterior canal in 96 patients, horizontal canal in 4 and anterior canal in one. On reviewing records of patients only $19 \%$ had been given diagnosis of BPPV. All patients had been treated with labyrinthine sedatives and other medications and none had been offered CRM. Eighty four percent patients had undergone various unnecessary investigations.

Conclusion: A vast majority of patients with BPPV don't get an accurate diagnosis in their first contact with health care professionals. Most of the patients undergo unnecessary investigations.CRMs like Epley's maneuver are not offered to BPPV patients even though they are the standard of care in this condition.

Key words: BPPV, Epley's maneuver, Dix Hallpike test,vertigo.

JMS: 2019; 22(1):37-42 DOI: https://doi.org/10.33883/jms.v22i1.419

\section{INTRODUCTION}

Benign paroxysmal positional vertigo (BPPV) is considered to be the most common type of vertigo with a lifetime prevalence of $2.4 \%$. The posterior semicircular canal (PSC), being the most gravity-dependent canal, accounts for 85 to $95 \%$ of the BPPV cases. ${ }^{2}$ Early diagnosis and treatment with canalith repositioning maneuvers CRMs like Epley's maneuver leads to resolution of symptoms in most of these patients. ${ }^{3}$ In spite of being a common and disabling medical problem, there is often significant time delay in the diagnosis and treatment of BPPV., The suboptimal management of BPPV has adverse impact on

$\begin{array}{lll} & \text { Access this article online } \\ & \end{array}$

quality of life especially if it is recurring. The diagnosis of BPPV is made by a simple bedside test known as DixHallpike maneuver (DHM). ${ }^{6}$ Despite having a strong evidence supporting the role of DHM and CRMs in managing BPPV, these maneuvers are underutilized. ${ }^{7,8}$

\section{MATERIALAND METHODS}

A prospective study was conducted in the outpatient clinic

Correspondence:

Dr. Sheikh Hilal Ahmad, M.D, DNB

Consultant, Department of Neurology, GMC Srinagar, J\&K.

Email:drhilal@gmail.com

How to cite this article: Sheikh HA, S Bashir A, Tak S, Naqash H. Optimal management of benign paroxysmal positional vertigo patients: An unmet need. jms [Internet]. 2019Mar.29 [cited 2019Apr.8];22(1). Available from: http://www.jmsskims.org/ index.php/jms/article/view/419

Received: 04-03-2019 Accepted: 25-03-2019 
Sheikh HA; et al; Optimal management of benign paroxysmal positional vertigo patients

of Department of Neurology in a tertiary care center referral hospital in Kashmir, north India. All patients who presented with symptoms of vertigo as their one of the main complaint from $1^{\text {st }}$ January 2017 to $31^{\text {st }}$ December 2018 were evaluated.

Patients aged less than 18 or above 80 years were excluded. Patients having physical disabilities in which it was not possible to perform diagnostic and treatment maneuvers were also excluded from the study.

Detailed history of vertigo, its duration, precipitating factors, associated symptoms like nausea, vomiting, tinnitus, deafness were recorded. Other neurologic symptoms like diplopia, dysarthria, ataxia, weakness of any part of body, bulbar weakness and sensory symptoms were looked for to rule out any central cause for vertigo. Past history was elicited especially for any headaches, trauma, ear surgeries, and any similar episodes of vertigo. Ear was examined for any pathology and whenever indicated ENT examination, fistula test and hearing tests were done. A detailed neurological examination was done to look for any central cause of vertigo. Other causes of vertigo apart from BPPV both central and peripheral were treated as per hospital protocol and were excluded from the study. Postural drop of Blood pressure was checked to rule out any symptoms because of postural dizziness. BPPV diagnosis was made on the criteria laid down previously after doing standard provocative maneuvers. ${ }^{9,10}$ Dix-Hallpike (DH) test was done to detect posterior canal BPPV. Roll test was carried out to detect lateral canal BPPV. ${ }^{9}$ Anterior canal BPPV was confirmed by positional nystagmus elicited immediately or after a latency of one or few seconds in the supine straight head-hanging position, beating predominantly vertically downward and lasting $<1 \mathrm{~min} .{ }^{9}$

Patients diagnosed to be having BPPV were treated with Canalith Repositioning Maneuvers (CRM). Epley's maneuver was performed in patients with posterior canal BPPV while Barbeque maneuver was done for lateral canal BPPV. Patients were reviewed after 7 days ; positional test was repeated and if symptoms persisted CRM was repeated again and patients re-examined weekly till BPPV was cured. Criteria for successful cure were relief of vertigo and negative positional test.

History of previous treatment was reviewed; and following things were recorded including diagnosis made, delay between onset of symptoms and reporting to us, medications prescribed, investigations done, and any procedures attempted before being referred was recorded.

\section{RESULTS}

Out of 261 patients who presented with vertigo as one of their main complaints during this period ;101 patients were diagnosed and treated as BPPV.Out of this 77 were females and 24 were males with M:F ratio as 1:3.2 in our population as shown in (table 1).Average age of this cohort was 52 years ; with minimum being 21 and maximum being 80 . Most patients ( 31 out of 101) were seen in age group $51-60$ years as shown in (table 1). The causes of BPPV identified in our patients are described in ( table 2) with most common being idiopathic (68 patients out of 101). Associated cervical spondylosis was seen in $9 \%$.Ten percent had history of similar episodes in past and $15 \%$ had recurrence on follow up. On doing the Dix Hallpike test 96 patients were having posterior canal BPPV. Horizontal canal BPPV was diagnosed in 4 patients on roll test and one patient was diagnosed as having anterior canalalithiasis on head hanging test. All the patients were followed weekly till they recovered.CRMs was done in all patients; 72 patients were cured by single CRM, while 12 patients needed more than one session. In 9 patients Brandt Daroff exercises were advised after CRMs, while as 8 patients with underlying inner ear disease were given additional medications .

On reviewing the records and referral notes only 19 patients were given correct diagnosis of BPPV ;out of these in 5 patients the diagnosis was based upon the Dix Hallpike test which was recorded as positive. Though the details about which side and which canal was involved was not documented .In the rest of the 14 patients Dix Hallpike test had not been done as was clear by no record on the prescription or referral notes and by history of no such maneuver having been done on the patient by the treating physician. Furthermore the canalith repositioning maneuver was not done as per the records. The rest of the patients were given various diagnoses as shown in (table 3 ). In the 25 patients who were given diagnosis of "peripheral vertigo"; the Dix Hallpike test was not done in these patients as was clear by no record on the prescription or referral notes and by history of no such maneuver having being done on the patient. And further Canal repositioning maneuver was not offered to these patients as well. The patients in our 
Sheikh HA; et al; Optimal management of benign paroxysmal positional vertigo patients

study had been attended to before visiting our department by doctors in various specialties which included medical officers in 36 patients, physicians in 27 patients,ENT surgeons in 22 patients and 17 patients were seen by neurologists .Investigations were done in 84 patients ; the various types of investigations done in these patients are shown in (table 4); many patients underwent more than one investigation .The medications which were given or procedures done are shown in (table 4). The reason for visit to our department varied ; with most common reason being no relief from previous treatment in 60 out of 101 patients and only partial relief in 41 patients. Among these patients other reasons for referral was to rule out neurological cause of vertigo in 28 patients. The delay before getting a correct diagnosis or correct treatment in patients of BPPV was not uniform and ranged from less than 2 weeks to more than 1 year and is shown in (table 5).

\section{DISCUSSION}

In our study out of 261 patients presenting to us with vertigo as one of the main complaints 101 (39\%) had BPPV. In two similar studies from Asian sub continent the percentage of BPPV presenting to two ENT departments was $47 \%$ and $39.5 \%{ }^{4,11}$ The male: female ratio was $1: 3.2$ which shows female predominance in this disorder as has been described in other studies.$^{1,4,11}$ The mean age of the patients was 52 years with maximum number of patients in age group 51 to 60. In an epidemiological study from Germany the mean age was 49 (SD 13 years). ${ }^{1}$ In other observational studies like ours mean age was similar to as seen by us. ${ }^{4,11}$

Posterior canal BPPV (PC-BPPV) was diagnosed in 96 patients (out of 101), 4 patients were diagnosed of horizontal BPPV and in one patient anterior canal BPPV was diagnosed. The PC BPPV is considered the single most type of BPPV as has been shown in literature and is diagnosed by Dix Hallpike test . ${ }^{12}$ The sensitivity of the DixHallpike test has been estimated at 48 to $88 \%$ according to a structured review of published literature. ${ }^{13}$ Repeated testing in separate occasions may be necessary to avoid missing the diagnosis. Failure to diagnose BPPV may lead to costly diagnostic work up. ${ }^{14}$ Whereas a positive test should be considered sufficient for the diagnosis of BPPV in the clinical setting, a negative test should not rule out BPPV completely. ${ }^{12}$

The cause of BPPV was looked into in our study and though majority of cases were idiopathic 68 patients, 18 patients gave history of trauma ( table 2).As is reported in literature apart from trauma and vestibular neuronitis; in most patients with benign paroxysmal positional vertigo, no antecedent association is found. ${ }^{10}$ In a similar study from southern India, out of 172 BPPV patients, 94\% cases were idiopathic, $4 \%$ had history of trauma, $2 \%$ had history of neck surgery and $1 \%$ had dental extraction. ${ }^{11}$

The important point in our study was that out of the 101 patients only 19 patients had been given diagnosis of BPPV and Dix Hallpike test was done only in 5 of these 19 patients as per records and history from patients. In the rest of the 14 patients Dix Hallpike test had not been done as was clear by no record on the prescription or referral notes and by history of no such maneuver having been done on the patient by the treating physician. Thus in these patients the diagnosis appeared to have been made by characteristic history which is usually given by patients having BPPV. Furthermore, the canalith repositioning maneuver was not offered to any of them. Though the BPPV falls into the management domain of neurologists and ENT surgeons, we found that patients who had visited these specialists were not offered Canal repositioning maneuver even after making a correct diagnosis of BPPV.

The most common diagnosis given to these patients before visiting us as shown in ( table 3 ) was cervicogenic vertigo (29 out of 101) followed by peripheral vertigo in 26 patients .Medications was prescribed in all patients and betahistine was prescribed in 76 patients. Cervical collar was prescribed presumably to treat cervicogenic vertigo in 26 patients. This points to a knowledge gap in medical community that cervicogenic vertigo is a common cause of vertigo .The cervicogenic vertigo is not a very well described cause of vertigo and whether cervical vertigo is an independent entity remains controversial.$^{15,16}$ It is now described in literature as cervical dizziness in patients with cervical spine pathology and even then is a diagnosis of exclusion. $^{17}$

There was a substantial delay in correct diagnosis of more than one year in 17 patients and in other patients as shown in (table 5) there was an unnecessary delay in diagnosing BPPV. Delay in diagnosing BPPV has been recognized in other studies as well; Arshad M el al, John H GM et al ,Wang $\mathrm{H}$ et al reported delay of 19 months, 3 months and 70 
Sheikh HA; et al; Optimal management of benign paroxysmal positional vertigo patients

Table 1: Age and sex distribution of BPPV patients.

\begin{tabular}{|l|l|l|l|}
\hline Age group & Females $(\mathbf{n}=\mathbf{7 7})$ & Males $(\mathbf{n}=\mathbf{2 4})$ & Total $(=\mathbf{1 0 1})$ \\
\hline $18-20$ & Nil & nil & 0 \\
\hline $21-30$ & 3 & nil & 3 \\
\hline $31-40$ & 9 & 3 & 12 \\
\hline $41-50$ & 21 & 6 & 27 \\
\hline $51-60$ & 24 & 9 & 33 \\
\hline $61-70$ & 15 & 4 & 19 \\
\hline $71-80$ & 5 & 2 & 7 \\
\hline
\end{tabular}

Table 2: Showing the frequency of various causes of BPPV

\begin{tabular}{|l|l|}
\hline History of trauma & 15 \\
\hline Tooth extraction & 3 \\
\hline Immobilization of head ( post procedure) and neck & 4 \\
\hline Underlying inner ear disease & 11 \\
\hline Idiopathic & 68 \\
\hline
\end{tabular}

Table 3: Various diagnosis given to patients before reaching to our hospital.

\begin{tabular}{|l|l|}
\hline Referral Diagnosis/Previous diagnosis & \\
\hline Stroke & 5 \\
\hline Cervicogenic vertigo & 29 \\
\hline Peripheral Vertigo & 25 \\
\hline BPPV & 19 \\
\hline Vertigo( not classified) & 17 \\
\hline Vertebro-basilar insufficiency & 6 \\
\hline
\end{tabular}

Table 4: Various investigations done and treatment given before visiting to our department.

\begin{tabular}{|l|l|l|l|}
\hline Investigations & Number of patients & Treatment given & $\begin{array}{l}\text { Number of } \\
\text { patients }\end{array}$ \\
\hline X-ray cervical spine & 45 & Betahistine only & 45 \\
\hline CT head & 25 & $\begin{array}{l}\text { Betahistine with } \\
\text { cervical collar }\end{array}$ & 26 \\
\hline MRI Brain & 6 & Cinnarizine only & 14 \\
\hline MRI Cervical Spine & 3 & $\begin{array}{l}\text { Multiple } \\
\text { medications }\end{array}$ & 16 \\
\hline PTA & 18 & $\begin{array}{l}\text { Repositioning } \\
\text { Maneuver }\end{array}$ & 0 \\
\hline ECG & 35 & & \\
\hline MR Angiography & 3 & & \\
\hline
\end{tabular}


Sheikh HA; et al; Optimal management of benign paroxysmal positional vertigo patients

months respectively before diagnosis of BPPV ${ }^{4,5,11} \mathrm{We}$ did not look for the average delay because it would be misrepresentative of the whole cohort as the delay was not dispersed normatively. In 17 patients delay was more than 1 year though, which is large and could be because of relapsing course of this disorder per se.

In 84 patients before visiting our department various investigations were done. Most of these patients had underwent multiple investigations .Patients had been investigated for stroke with MRI and CT done in 31 patients; MR cervical spine had been done in 3 patients and MR Angiography of neck was done in 3 patients. Other investigations included ECG, X-ray cervical spine, pure tone audiometry. These investigation are not helpful in the diagnosis of BPPV. This seconds the point that there is a knowledge gap, regarding how to diagnose BPPV and how to manage it. A Cochrane review and five other metaanalyses show amply the evidence for the effectiveness of the Epley's maneuver for the treatment of posterior canal BPPV ${ }^{18,19}$ This translates into NNT to eliminate symptoms in range from 1.4 to 3.7 ; which is among the most substantial effect achievable in clinical medicine. ${ }^{6}$

There seem to be barriers at multiple levels in managing a patient with BPPV .Firstly, many patients of BPPV are given incorrect diagnoses like "cervicogenic vertigo" which shows a knowledge gap in understanding the disease symptomatology and pathology. Second barrier we feel is that after, entertaining a preliminary diagnosis of BPPV or "peripheral vertigo" by the caregiver on history ,Dix Hallpike test is not done to confirm the diagnosis of BPPV in a majority of patients. Lastly canalith repositioning maneuvers is not offered probably to most of these patients .These patients are given symptomatic treatment with hope that there will be self repositioning of the otoconia .We would also want to mention it that this cohort reflects the perspective of the problem what we see from our side; there will be definitely patients who were properly managed and obviously did not visit us.

A cross-sectional survey done in emergency and nonemergency physicians ; to explore the attitude of these frontline healthcare providers towards the diagnosis and management of traumatic BPPV ( $t$ BPPV) in head injury patients found that diagnosis of t-BPPV itself is under recognized and the knowledge about management of $t-$
BPPV among frontline providers is suboptimal. ${ }^{6}$ The authors found that lack of knowledge about t-BPPV was identified as the main reason (55.9\%) for not probing the possibility of t-BPPV. ${ }^{6}$

The suboptimal management of BBPV patients by the health care providers has been previously studied and attributed to lack of knowledge and to lack of teaching to enhance skill to use physical maneuvers by frontline care providers. ${ }^{20,21}$ Furthermore, inappropriate use of radiological and laboratorial examinations to diagnose tBPPV was also observed. ${ }^{7.8}$

Thus there is need to make the medical community aware about how to diagnose and treat BPPV .And to ensure it is taught at undergraduate and postgraduate level in medical colleges.

\section{CONCLUSION}

A vast majority of patients with BPPV don't get an accurate diagnosis in their first contact with health care professionals. Most of the patients undergo unnecessary investigations .CRMs like Epley's maneuvers are not offered to BPPV patients even though they are the standard of care in this condition.

Conflict of interest : Nil.

Financial Source: Nil

\section{REFERENCES}

1. Von Brevern M, Radtke A, Lezius F, Feldmann M, Ziese T, Lempert T, Neuhauser H. Epidemiology of benign paroxysmal positional vertigo: A population based study. J Neurol Neurosurg Psychiatry. 2007;78(7):710715.

2. Parnes LS, Agrawal SK, Atlas J. Diagnosis and management of benign paroxysmal positional vertigo (BPPV). Canadian Medical Association Journal. 2003;169(7):681693.

3. Epley JM. Human experience with canalith repositioning maneuvers. Ann NY Acad Sci. 2001;942:179191.

4. Arshad M, Abbas S, Qureshi IA. Delay in diagnosis and treatment of benign paroxysmal positional vertigo in current practice. J Ayub Med Coll Abbottabad 2013;25(1-2):93-95.

5. Wang H, Yu D, Song N, Su K, Yin S. Delayed diagnosis 
Sheikh HA; et al; Optimal management of benign paroxysmal positional vertigo patients

and treatment of benign paroxysmal positional vertigo associated with current practice. Eur Arch Otorhinolaryngol. 2014;271(2):261264

6. Fife TD, Iverson DJ, Lempert T, Furman JM, Baloh RW, Tusa RJ, Hain TC, Herdman S, Morrow MJ, Gronseth GS. Practice parameter: Therapies for benign paroxysmal positional vertigo (an evidence-based review): Report of the Quality Standards Subcommittee of the American Academy of Neurology. Neurology. 2008;70(22):20672074.

7. Newman-Toker DE, Camargo CA Jr, Hsieh YH, Pelletier AJ, Edlow JA. Disconnect between charted vestibular diagnoses and emergency department management decisions: A cross-sectional analysis from a nationally representative sample. Acad Emerg Med. 2009;16(10):970977.

8. Bashir K, Alessai GS, Salem WA, Irfan FB, Cameron PA. Physical maneuvers: Effective but underutilized treatment of benign paroxysmal positional vertigo in the ED. Am J Emerg Med. 2014;32(1):9596.

9. von Brevern M, Bertholon P, Brandt T, Fife T, Imai T, Nuti D, Newman-Toker. Benign paroxysmal positional vertigo: Diagnostic criteria. J Vestib Res. 2015;25(34):105-17.

10. Furman JM, Cass SP .Benign paroxysmal positional vertigo. N Engl J Med. 1999;341(21):1590.

11. John HGM. Benign paroxysmal positional vertigo- A prospective study. J. Evid. Based Med. Healthc. 2017; 4(22), 1283-1286

12. Halker RB, Barrs DM, Wellik KE, Wingerchuk DM, Demaerschalk BM.Establishing a diagnosis of benign paroxysmal positional vertigo through the dix-hallpike and side-lying maneuvers: a critically appraised topic. Neurologist. 2008 May; 14(3):201-4.

13. Li JC, Li CJ, Epley J, Weinberg L. Cost-effective management of benign positional vertigo using canalith repositioning. Otolaryngol Head Neck Surg. 2000;122:334339.

14. Nguyen-Huynh AT. Evidence-based practice: management of vertigo. Otolaryngol Clin North Am. 2012;45(5):925-40.

15. Brandt T. Cervical vertigo: Reality or fiction? Audiol Neurootol 1996; 1:187-196. 8.

16. Yacovino DA. Cervical vertigo: Myths, facts, and scientific evidence. Neurologia 2012; 13:211-213.

17. Reiley A S, Vickory F M, Funderburg S E et al. Archives of Physiotherapy (2017) 7:12.

18. Hilton M, Pinder D. The Epley (canalith repositioning) maneuver for benign paroxysmal positional vertigo. Cochrane Database Syst Rev. 2004:CD00316

19. Teixeira LJ, Machado JN. Maneuvers for the treatment of benign positional paroxysmal vertigo: a systematic review. Braz J Otorhinolaryngol. 2006;72:130139.

20. Kerber KA. Benign paroxysmal positional vertigo: Opportunities squandered. Ann NY Acad Sci. 2015; 1343:106112.

21. Polensek SH, Tusa RJ, Sterk CE. The challenges of managing vestibular disorders: A qualitative study of clinicians' experiences associated with low referral rates for vestibular rehabilitation. Int $\mathrm{J}$ Clin Pract. 2009;63(11):16041612. 